\title{
OPEN Growth and autolysis of the kefir yeast Kluyveromyces marxianus in lactate culture
}

\author{
Shou-Chen Lo ${ }^{1 \bowtie}$, Chia-Yin Yang ${ }^{1}$, Dony Chacko Mathew ${ }^{2}$ \& Chieh-Chen Huang ${ }^{1,3,4 凶}$
}

Kluyveromyces marxianus is a yeast that could be identified from kefir and can use a broad range of substrates, such as glucose and lactate, as carbon sources. The lactate produced in kefir culture can be a substrate for $K$. marxianus. However, the complexity of the kefir microbiota makes the traits of $K$. marxianus difficult to study. In this research, we focused on $K$. marxianus cultured with lactate as the sole carbon source. The optimal growth and released protein in lactate culture were determined under different $\mathrm{pH}$ conditions, and the LC-MS/MS-identified proteins were associated with the tricarboxylic acid cycle, glycolysis pathway, and cellular stress responses in cells, indicating that autolysis of $K$. marxianus had occurred under the culture conditions. The abundant glyceraldehyde-3-phosphate dehydrogenase 1 (GAP1) was cocrystallized with other proteins in the cell-free fraction, and the low transcription level of the GAP1 gene indicated that the protein abundance under autolysis conditions was dependent on protein stability. These results suggest that lactate induces the growth and autolysis of $K$. marxianus, releasing proteins and peptides. These findings can be fundamental for $K$. marxianus probiotic and kefir studies in the future.

Kluyveromyces marxianus is frequently isolated from dairy products, such as cheese and kefir. It is consistently detected in certain kefir cultures ${ }^{1}$ and can be acquired from unpasteurized milk ${ }^{2}$. The long history of safe use of these products makes K. marxianus a generally recognized as safe (GRAS) yeast strain. In a recent review, $K$. marxianus was considered as a potential probiotic yeast ${ }^{3}$. K. marxianus can utilize a broad spectrum of carbon sources, including carbohydrates and organic acids, such as glucose, sucrose, lactose, fructose, galactose, xylose, lactic acid and malic acid ${ }^{4}$, making it suitable for use in the food industry. In kefir cultures, lactate can be a nonfermentable carbon source for K. marxianus. However, the complexity of the symbiotic bacteria and yeasts in kefir culture makes the interactivity of the microbiota difficult to study. To simplify the interaction between K. marxianus and lactate, we focused on the traits of the K. marxianus lactate culture.

Although several nonfermentable carbon sources can be used to grow K. marxianus, protein expression under these culture conditions is rarely discussed. Another issue with using nonfermentable carbon sources as substrates is autolysis. The known autolysis in Saccharomyces cerevisiae occurs after fermentable carbon sources are exhausted at stationary phase in the culture ${ }^{5}$. Substitution of a fermentable carbon source with a nonfermentable carbon source can lead to the formation of a stressful environment for yeast.

Lactate is a nonfermentable carbon source for yeast. It is known that some S. cerevisiae strains can express pectinase in the presence of lactate ${ }^{6}$. The induction of secreted pectinase expression implies that lactate can upregulate the expression of certain proteins in S. cerevisiae. Furthermore, both S. cerevisiae and K. marxianus can reduce lactate feedback inhibition of lactic acid bacteria ${ }^{7}$. Therefore, with lactate as the sole carbon source, K. marxianus could exhibit potential for biotechnological applications. The lactate uptake mechanism of $K$. marxianus involves uptake of lactate anions with a monocarboxylate uniport ${ }^{8}$. Hence, the lactate uptake efficiency depends on the $\mathrm{pH}$ of the culture medium for the dissociation of lactate. Culture conditions with nonfermentable carbon sources and low $\mathrm{pH}$ cause autolysis in S. cerevisiae during winemaking ${ }^{9}$. Autolysis of yeast leads to the release of low-molecular-weight compounds and peptides that impart additional flavor or sweetness to the wine $\mathrm{e}^{9,10}$. In this study, the K. marxianus strain Bot $3+7$ that was isolated from homemade kefir in Taiwan was classified by multilocus sequence typing ${ }^{11}$ and the proteins that were released from $K$. marxianus autolysis and the transcription level of the genes that encoded the high-abundance proteins were investigated. The total released proteins were analyzed by SDS-PAGE and liquid chromatography-tandem mass spectrometry (LC-MS/

${ }^{1}$ Department of Life Sciences, National Chung Hsing University, Taichung 402, Taiwan. ${ }^{2}$ Washington High School, Taichung 406, Taiwan. ${ }^{3}$ Program in Microbial Genomics, National Chung Hsing University, Taichung 402, Taiwan. ${ }^{4}$ Innovation and Development Center of Sustainable Agriculture, National Chung Hsing University, Taichung 402, Taiwan. ${ }^{\circledR}$ email: scl@dragon.nchu.edu.tw; cchuang@dragon.nchu.edu.tw 


\begin{tabular}{|c|c|c|c|}
\hline Medium & Initial $\mathrm{OD}_{600}$ & $\mathrm{OD}_{600}(5$ days $)$ & Protein concentration $(\mu \mathrm{g} / \mathrm{mL}, 5$ days $)$ \\
\hline $\mathrm{YNL}^{\mathrm{a}} \mathrm{pH} 3.9$ & $0.124 \pm 0.006^{\mathrm{c}}$ & $15.429 \pm 0.634$ & $59.112 \pm 10.694$ \\
\hline YNL pH 4.18 & $0.583 \pm 0.005$ & $19.008 \pm 0.025$ & $99.394 \pm 10.768$ \\
\hline YNL pH 4.8 & $0.2 \pm 0.0119$ & $5.813 \pm 0.192$ & $101.228 \pm 29.918$ \\
\hline YNL pH 5.2 & $0.172 \pm 0.007$ & $6.864 \pm 1.365$ & $178.528 \pm 50.534$ \\
\hline YNL pH 5.44 & $0.412 \pm 0.002$ & $5.780 \pm 0.020$ & $79.685 \pm 10.011$ \\
\hline YNL pH 6.23 & $0.208 \pm 0.005$ & $1.850 \pm 0.110$ & $75.185 \pm 9.579$ \\
\hline YNL pH $5.44+\mathrm{Mg}^{\mathrm{b}}$ & $0.482 \pm 0.004$ & $8.641 \pm 0.097$ & $22.290 \pm 10.122$ \\
\hline
\end{tabular}

Table 1. Growth of Kluyveromyces marxianus Bot $3+7$ and protein concentrations in different culture media. aYNL indicates synthetic medium with $2 \%$ lactic acid as a carbon source. ${ }^{b} 0.2 \mathrm{M} \mathrm{MgCl}_{2}$ was present in the YNL medium. ${ }^{\mathrm{c} T h e}$ data are expressed as the mean \pm standard deviation; $\mathrm{n}=3$ independent biological samples.

MS). The results showed that maximum protein release occurred in culture medium at $\mathrm{pH} 5.2$, and the most abundant proteins were identified.

\section{Results}

Classification of $K$. marxianus Bot $3+7$ by multilocus sequence typing. To classify the isolated $K$. marxianus Bot $3+7$ strain, five K. marxianus housekeeping gene sequences, IPP1, TFC1, GPH1, GSY2 and SGA1, were amplified by polymerase chain reaction according to previous publication ${ }^{11}$ and analyzed at (kmarxianusMLST.ucc.ie $)^{11}$. The results indicate that $K$. marxianus Bot $3+7$ strain was most related to K. marxianus CCT 7735 strain which was isolated from regional Brazilian dairy industry wastewater ${ }^{12}$ (Supplementary Fig. S1).

The initial $\mathrm{pH}$ value of the lactate culture medium affects the growth of $K$. marxianus. The K. marxianus Bot $3+7$ strain was cultured in YPD medium for two days as a seed culture. Then, synthetic yeast culture medium with lactate as the sole carbon source, YNL, with different initial $\mathrm{pH}$ values was used for batch cultivation of the K. marxianus strain for five days. Although trace of YPD medium would be added into the synthetic medium culture, the results showed no difference from the culture with washed cell pellets under carbon source low concentration conditions (Supplementary Fig. S2). Therefore, the trace of YPD medium was not consider to affect the growth and autolysis in the experiments. On the other hand, the seed culture of yeast descended easily and made the inoculation hard to be consistent (Table 1). However, the values of $\mathrm{OD}_{600}$ increased at least above fivefold after 5 days culture, therefore the small variation of the initial values of $\mathrm{OD}_{600}$ should not affect the results. The growth curves and the released protein concentrations are shown in Fig. 1a,b. Optimal growth was observed at $\mathrm{pH} 4.18$ (optical density at $\left.600 \mathrm{~nm}\left(\mathrm{OD}_{600}\right)=19\right)$ (Table 1). Upon cultivation with YNL medium at $\mathrm{pH}$ values higher than 4.8 , the cell concentration of the $K$. marxianus strain decreased (Table 1). This might be because the dissociation of lactate anions decreased with increasing $\mathrm{pH}$ in the medium. The consumption of lactic acid would also increase $\mathrm{pH}$ values to about 7.6 during cultivation at $72 \mathrm{~h}$ (Supplementary Fig. S3a,b). However, the high $\mathrm{pH}$ values would not affect the cell viability in the first four days of culture (Supplementary Fig. S3c). To confirm if the K. marxianus strain could grow at pH 7.6, different carbon sources, such as glycerol, glucose and lactic acid, were used as carbon sources to culture the yeast strain (Supplementary Fig. S4). These results indicate that the cell viability of the yeast strain was not affected by $\mathrm{pH}$ values from 4.5 to 7.6 (Supplementary Figs. S3c, S4b).

Protein released to the culture medium. Table 1 shows that the concentration of protein released to the culture medium was associated with the initial $\mathrm{pH}$ of the culture medium. Maximum protein release was observed at $\mathrm{pH} 5.2(178 \mu \mathrm{g} / \mathrm{mL}$ ) (Table 1$)$. While using glycerol as carbon sources, the concentrations of protein released to the culture medium were no more than $10 \mu \mathrm{g} / \mathrm{mL}$ at $\mathrm{pH} 4.0, \mathrm{pH} 4.9$ and $\mathrm{pH} 6.3$ (Supplementary Fig. S5). These results indicate that using lactic acid as carbon sources would induce some biological processes different from using glycerol as carbon sources. Despite the concentrations of released protein were different, it was hard to tell the differences of the cell morphology between these two culture conditions under microscope (Supplementary Fig. S6). According to Nambu-Nishida et al.s report ${ }^{13}$, the divalent metal ion $\mathrm{Mg}^{2+} \mathrm{may}$ affect many cellular and biological processes by changing the membrane permeability. In a previous study, the presence of $\mathrm{MgCl}_{2}$ decreased autolysis in S. cerevisiae ${ }^{14}$. Therefore, the presence of $\mathrm{Mg}^{2+}$ ions might help the $K$. marxianus strain grow with lactate and decrease autolysis. In the presence of $0.2 \mathrm{M} \mathrm{MgCl}_{2}$, the final cell concentration $\left(\mathrm{OD}_{600}\right)$ at $\mathrm{pH} 5.44$ increased from 5.78 to 8.64, and the released protein concentration decreased from 79.6 to $22.2 \mu \mathrm{g} / \mathrm{mL}$ (Fig. 1c,d, Table 1 ).

Culture medium filtrate and protein concentration. The released protein level in the culture medium was too low for direct analysis by SDS-PAGE or LC-MS/MS. The culture media were first filtered with membranes with a molecular weight cutoff of $3 \mathrm{k}$ as described in the "Materials and methods" section. The proteins were concentrated 20-fold for SDS-PAGE analysis (Supplementary Fig. S7). However, the amount of protein was not suitable for total protein LC-MS/MS analysis. In order to have more reliable results, the condition with small variation of protein concentration was used in the experiment. Therefore, $300 \mathrm{~mL}$ of culture medium (at $\mathrm{pH} 5.44$ instead of $\mathrm{pH}$ 5.2) in another batch experiment of $K$. marxianus Bot $3+7$ was collected to obtain more 
a

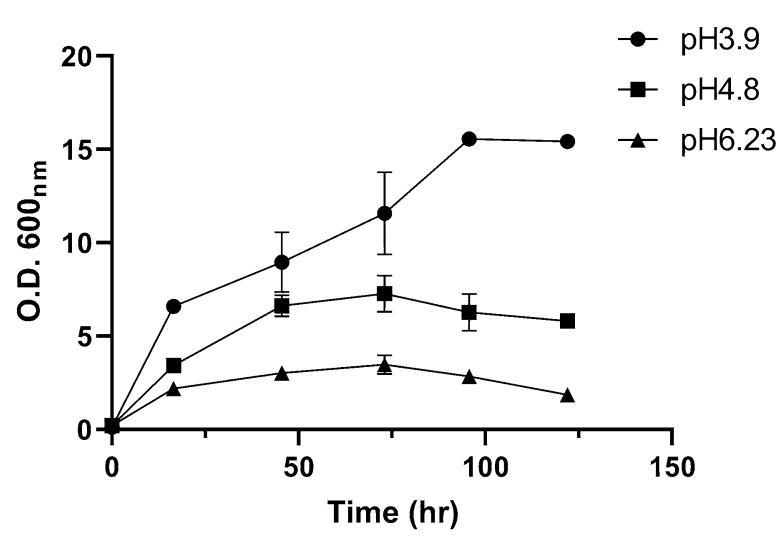

c

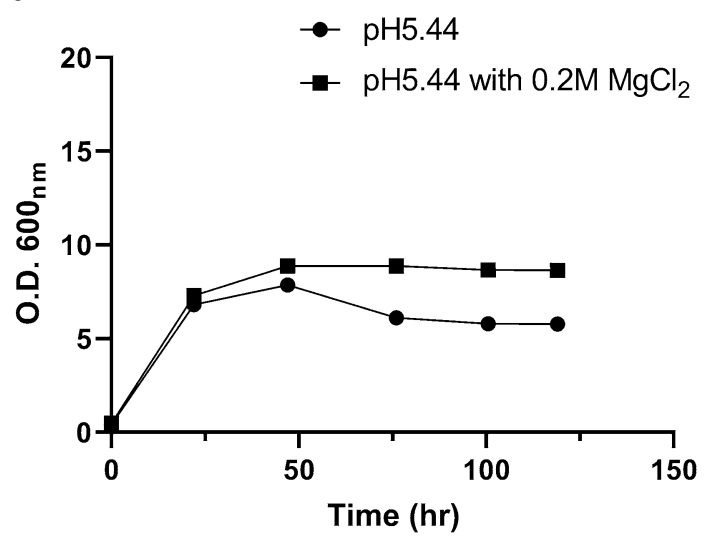

b

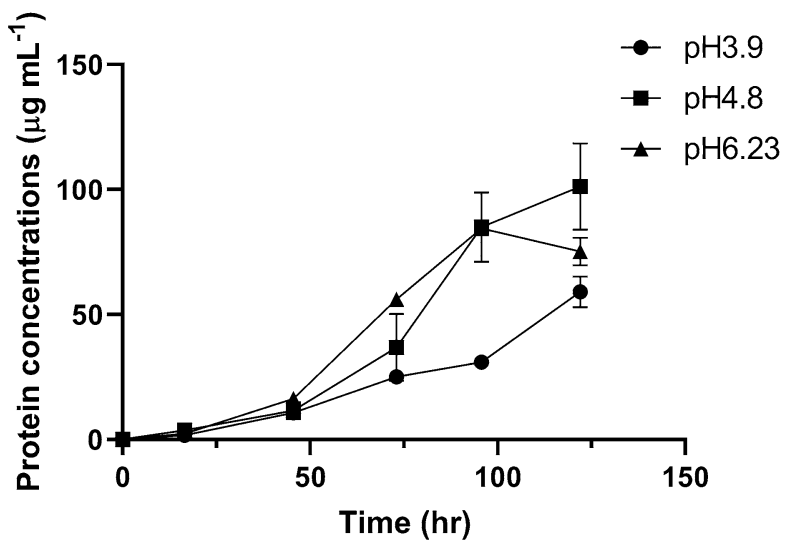

d

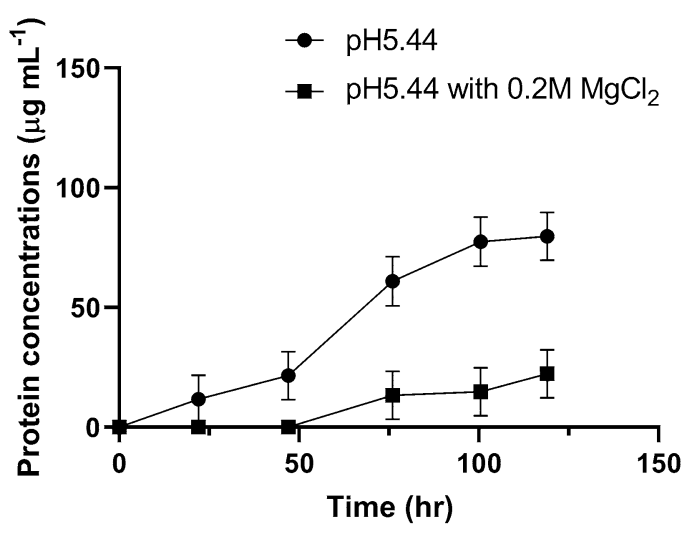

Figure 1. Growth curves and released protein concentrations of $K$. marxianus strain Bot $3+7$ at different $\mathrm{pH}$ values or with $\mathrm{Mg}$ supplementation. (a) Growth curve of $K$. marxianus strain Bot $3+7$ at $\mathrm{pH} 3.9, \mathrm{pH} 4.8$, and $\mathrm{pH}$ 6.23. (b) Released protein concentration of $K$. marxianus strain $\operatorname{Bot} 3+7$ at $\mathrm{pH} 3.9$, pH 4.8, and pH 6.23. (c) Growth curve of K. marxianus strain Bot $3+7$ at pH 5.44 in the presence or absence of $0.2 \mathrm{M} \mathrm{MgCl}_{2}$. (d) Released protein concentration of $K$. marxianus strain Bot $3+7$ at $\mathrm{pH} 5.44$ in the presence or absence of $0.2 \mathrm{M}$ $\mathrm{MgCl}_{2}$. This image was created by using GraphPad Prism version 8.2.1 (https://www.graphpad.com/scientificsoftware/prism/).

protein. Approximately $0.1 \mathrm{mg} / \mathrm{mL}$ protein was obtained on the 12 th day ( $288 \mathrm{~h}$ ) of incubation (data not shown). It took more than twice as much time to reach the optimum concentration of released protein than it did with the 3 -mL culture (Fig. $1 \mathrm{~b}$ ). The medium was collected at $120 \mathrm{~h}$ and $288 \mathrm{~h}$, filtered through a $0.2-\mu \mathrm{m}$ pore size membrane and stored at $4{ }^{\circ} \mathrm{C}$ for further concentration and desalting. Noticeable small crystals appeared in the storage medium of the 288-h sample after 2 days (Fig. 2a). The crystals formed in the culture medium did not dissolve in $\mathrm{ddH}_{2} \mathrm{O}$ and methanol but could be dissolved in Bradford reagent and low-pH solutions, such as $10 \%$ acetic acid. The crystals dissolved in Bradford reagent were analyzed by SDS-PAGE, and there were two major bands at approximately $37 \mathrm{kDa}$ and $27 \mathrm{kDa}$ (Fig. 2b) along with other faint bands. To determine the identity of the proteins, the major bands were excised and sent for LC-MS/MS analysis. Peptide fingerprinting of the $37-\mathrm{kDa}$ and $27-\mathrm{kD}$ a proteins identified both proteins as glyceraldehyde 3-phosphate dehydrogenase 1 (GAP1) in K. marxianus (Fig. 3). Some protein regions were unmatched, which might have been due to insufficient in-gel trypsin digestion. Nonetheless, a notable fingerprint peptide (VAVFQEK) was absent just before the second acid cleavage site in the peptide (aspartic acid-proline, 79D-80P) among the 27-kDa peptide fingerprints compared with the $37-\mathrm{kDa}$ fingerprints (Fig. 3, Supplementary Table S1). The molecular mass of the N-terminal peptides (residues 1-79) after acid cleavage of G3P1 was approximately $9 \mathrm{kDa}$. These results suggest that the 27-kDa protein was derived from the acid cleavage of GAP1 when the protein was dissolved in acidic solutions.

General proteomics of released protein from $K$. marxianus in lactate culture medium. Analysis of total released protein with LC-MS/MS. Nonetheless, protein crystals were formed, and the proteins in YNL medium at $\mathrm{pH} 5.44$ were further desalted and concentrated to at least $3 \mu \mathrm{g} / \mu \mathrm{L}$ for LC-MS/MS analysis as described in the "Materials and methods" section. Note that since the samples were released by autolysis, the proteins would be cleaved at unexpected cleavage sites. To maintain reliability of the LC-MS/MS analysis, only trypsin cleavage-derived peptides were used as fingerprints to identify proteins. Therefore, the numbers of 
(a)

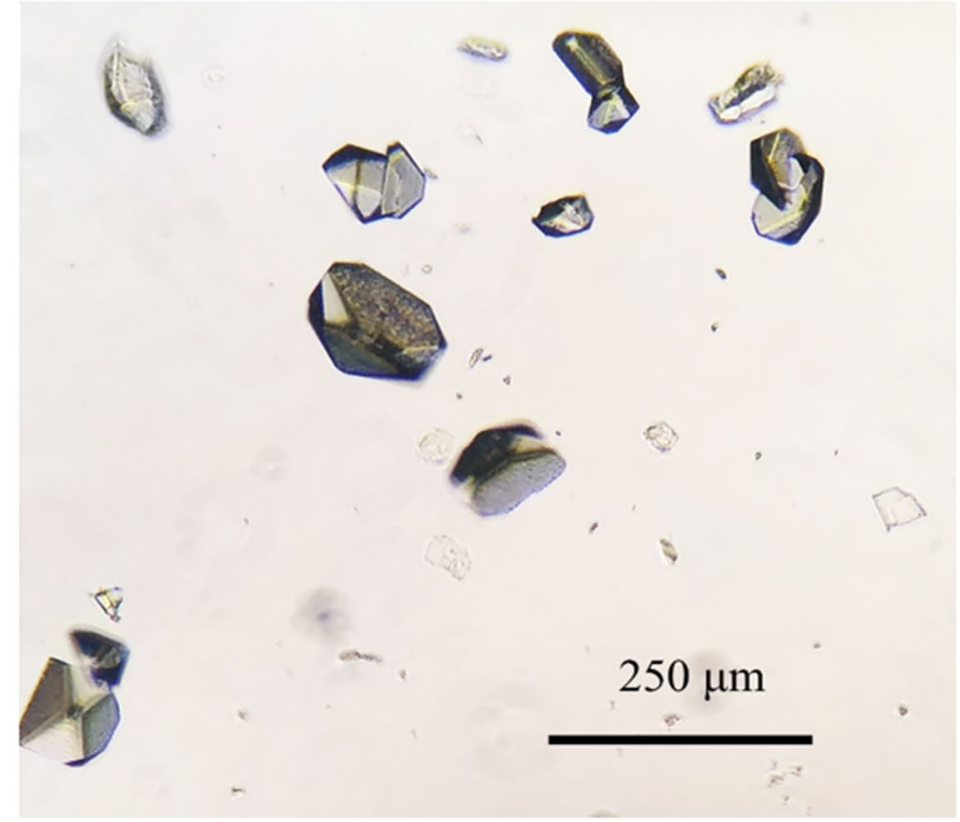

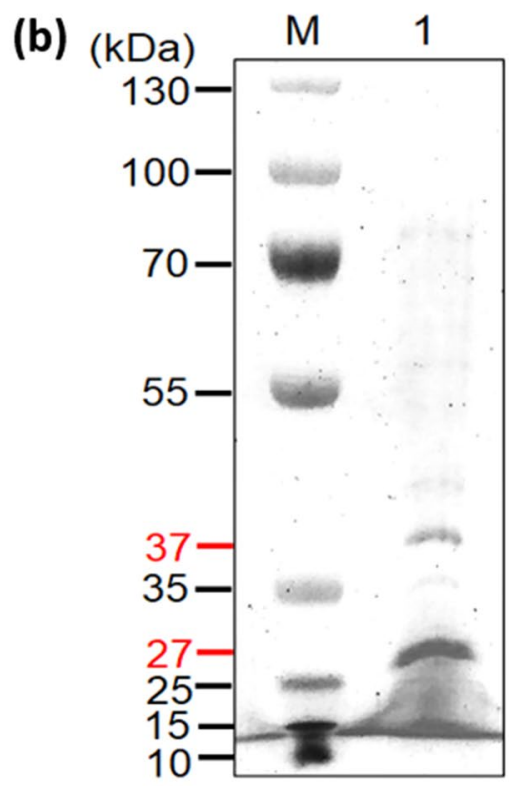

Figure 2. Microscopic photograph and SDS-PAGE analysis of protein crystals from the YNL culture filtrate at pH 5.44. (a) Microscopic photograph of the protein crystals. (b) SDS-PAGE analysis of the YNL culture filtrate at $\mathrm{pH}$ 5.44. Lanes $\mathrm{M}$ and 1 indicate the protein ladder and protein crystals, respectively. This image was edited by using Microsoft Office Professional 2019 PowerPoint (https://www.microsoft.com/zh-tw/microsoft-365/p/offic e-\%E5\%B0\%88\%E6\%A5\%AD\%E7\%89\%88-2019/cfq7ttc0k7c5?activetab=pivot\%3aoverviewtab).

1
72-78

$117-124$
198-212 217-231 249-256

301 a.a.

GAP1

DP

DP

$37 \mathrm{kDa}$

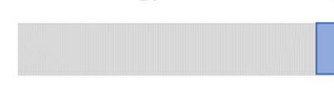

$27 \mathrm{kDa} \mid \sim 9 \mathrm{kDa}$

Figure 3. Schematic diagram of the peptides that matched to glyceraldehyde-3-phosphate dehydrogenase (GAP1) from the 37-kDa and 27-kDa protein bands in SDS-PAGE analysis. This image was created by using Microsoft Office Professional 2019 PowerPoint (https://www.microsoft.com/zh-tw/microsoft-365/p/office-\% E5\%B0\%88\%E6\%A5\%AD\%E7\%89\%88-2019/cfq7ttc0k7c5?activetab=pivot\%3aoverviewtab).

matched peptides were lower than expected. However, the identified proteins could be confirmed in the autolysis medium. A total of 313 and 513 proteins were matched in the NCBI K. marxianus protein database in the 120-h and 288-h culture media, respectively. However, only 295 and 473 of the identified proteins in the 120-h and 288h culture media, respectively, could be mapped to UniProtKB for further Gene Ontology (GO) classification. Generally, the mapped proteins in the 120-h medium were similar to those in the 288-h medium, but some of the proteins were missing, such as actin, which could be found in only the 120 -h cell pellets and the 288 -h medium, not in the 120-h medium (Supplementary Tables S2-S4). This was probably because the autolysis process was closer to completion in the 288 -h samples than in the 120 -h samples.

Metabolism. Proteins associated with the tricarboxylic acid cycle, gluconeogenesis, and pentose phosphate pathway were identified (Supplementary Tables S3, S4). Among other carbohydrate metabolism processes, proteins related to galactose metabolism and exoinulinase were identified (Supplementary Tables S3, S4). Two proteins were identified as being related to lactate metabolism (D-lactate dehydrogenase [cytochrome] 2 and cytochrome b2) (Supplementary Tables S3, S4).

Stress response. The identified proteins included several proteins that were related to cellular stress responses, such as responses to starvation (4 proteins in the 120 -h medium, 5 proteins in the 288 -h medium), osmotic stress ( 3 proteins in the 120 -h medium, 8 proteins in the 288 -h medium), and oxidative stress (16 proteins in the 120 -h medium, 17 proteins in the 288 -h medium). Notably, a $12 \mathrm{kDa}$ heat shock protein (HSP12) was related to both 


\begin{tabular}{|c|c|c|c|c|c|c|c|c|c|c|c|}
\hline \multirow[b]{2}{*}{ NCBI accession number } & \multirow[b]{2}{*}{ Protein name } & \multirow[b]{2}{*}{$M_{r}$} & \multicolumn{3}{|c|}{$120 \mathrm{~h}$ pellet } & \multicolumn{3}{|c|}{$120 \mathrm{~h}$ medium } & \multicolumn{3}{|c|}{$288 \mathrm{~h}$ medium } \\
\hline & & & Matches & Sequences & emPAI $^{a}{ }^{a}$ & Matches & Sequences & emPAI\% & Matches & Sequences & emPAI $\%$ \\
\hline BAO39229.1 & $\begin{array}{l}12-\mathrm{kDa} \text { heat shock } \\
\text { protein }\end{array}$ & 11,193 & $34(28)$ & $8(7)$ & 5.68 & $40(37)$ & $9(8)$ & 4.76 & $54(52)$ & $10(9)$ & 18.7 \\
\hline P84998.1 & $\begin{array}{l}\text { Glyceraldehyde-3-phos- } \\
\text { phate dehydrogenase } 1\end{array}$ & 35,231 & $76(70)$ & $17(17)$ & 2.32 & $55(46)$ & $15(14)$ & 0.47 & $99(90)$ & $20(19)$ & 3.51 \\
\hline BAO38084.1 & Enolase & 46,773 & $63(55)$ & $20(19)$ & 0.9 & $168(141)$ & $30(26)$ & 2.86 & $128(115)$ & $20(19)$ & 2.3 \\
\hline BAO40149.1 & $\begin{array}{l}\text { Triosephosphate } \\
\text { isomerase }\end{array}$ & 26,979 & $29(25)$ & $13(11)$ & 0.88 & $93(84)$ & $23(22)$ & 4.65 & $48(45)$ & $15(14)$ & 1.43 \\
\hline BAO38162.1 & Phosphoglycerate kinase & 44,418 & $25(23)$ & $13(13)$ & 0.32 & $135(123)$ & $29(28)$ & 1.66 & $84(76)$ & $19(19)$ & 1.35 \\
\hline BAO39929.1 & Transaldolase & 36,452 & $33(29)$ & $15(15)$ & 0.71 & $102(87)$ & $28(25)$ & 2.32 & $41(37)$ & $18(18)$ & 1.21 \\
\hline BAP70103.1 & $\begin{array}{l}\text { Phosphoglycerate } \\
\text { mutase } 1\end{array}$ & 27,480 & $36(31)$ & $11(11)$ & 1.18 & $63(52)$ & $14(13)$ & 1.28 & $44(42)$ & $12(11)$ & 1.16 \\
\hline BAO42678.1 & Heat shock protein SSA3 & 70,036 & $46(39)$ & $21(20)$ & 0.4 & $119(108)$ & $29(29)$ & 0.68 & $93(86)$ & $27(26)$ & 0.81 \\
\hline BAO40152.1 & Heat shock protein 26 & 21,932 & $25(24)$ & $6(6)$ & 0.35 & $22(21)$ & $6(6)$ & 0.25 & $49(46)$ & $7(7)$ & 0.7 \\
\hline Q9P4C2.3 & Alcohol dehydrogenase 2 & 36,945 & $21(15)$ & $12(11)$ & 0.32 & $27(23)$ & $14(13)$ & 0.29 & $42(38)$ & $16(15)$ & 0.67 \\
\hline BAO40412.1 & $\begin{array}{l}\text { Fructose-bisphosphate } \\
\text { aldolase }\end{array}$ & 39,472 & $27(25)$ & $12(11)$ & 0.25 & $53(49)$ & $17(16)$ & 0.43 & $57(53)$ & $14(14)$ & 0.62 \\
\hline QGN17490.1 & Pyruvate decarboxylase & 61,862 & $48(42)$ & $19(18)$ & 0.41 & $67(57)$ & $20(18)$ & 0.42 & $68(61)$ & $20(19)$ & 0.6 \\
\hline CAA42785.1 & Alcohol dehydrogenase & 41,661 & $54(47)$ & $14(12)$ & 0.51 & $31(27)$ & $12(12)$ & 0.26 & $55(52)$ & $11(11)$ & 0.59 \\
\hline BAO39040.1 & Elongation factor 2 & 93,293 & $42(33)$ & $20(17)$ & 0.17 & $71(61)$ & $27(25)$ & 0.18 & $108(95)$ & $33(31)$ & 0.56 \\
\hline BAO39872.1 & $\begin{array}{l}\text { D-arabinose dehydroge- } \\
\text { nase }[\mathrm{NAD}(\mathrm{P})+] \text { heavy } \\
\text { chain }\end{array}$ & 38,883 & $10(8)$ & $8(8)$ & 0.15 & $9(7)$ & $7(5)$ & 0.05 & $46(43)$ & $13(13)$ & 0.55 \\
\hline
\end{tabular}

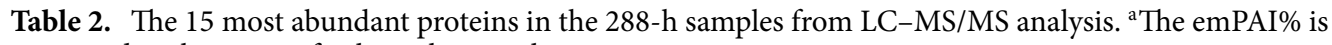
presented as the mean of at least three replicates.

osmotic and oxidative stress; therefore, it could be counted as only 1 protein, making the total 22 in the 120 -h medium and 29 in the 288 -h medium. A total of 11 and 13 proteins (including heat shock proteins and chaperones) in the 120-h and 288-h media, respectively, that help in protein folding and refolding were identified in the samples (Supplementary Tables S3, S4).

Abundance of identified proteins. The protein abundance is presented as a percentage of the exponentially modified protein abundance index (emPAI\%) $)^{15}$, and the 15 most abundant proteins $(\mathrm{emPAI} \%>0.5)$ in the 288-h medium are listed in Table 2. Note that several proteins, such as enolase and triosephosphate isomerase, had a higher emPAI\% in the 120 -h medium than in the 288 -h medium. This indicates that the released proteins were degraded during autolysis. Therefore, these 15 most abundant proteins in Table 2 were relatively stable proteins in the experiments. The major groups of proteins were related to metabolic pathways and the heat shock response. GAP1, enolase (ENO), phosphoglycerate kinase (PGK), phosphoglycerate mutase 1 (GPM1), fructose-bisphosphate aldolase (FBA1) and pyruvate decarboxylase (PDC1) were related to the gluconeogenesis pathway. Heat shock proteins, including HSP12, heat shock protein 26 (HSP26), and heat shock protein SSA3 (SSA3), were associated with the response to stress conditions. The other proteins were triosephosphate isomerase (TPI1), transaldolase (TAL1), alcohol dehydrogenase 2 (ADH2), alcohol dehydrogenase (adh), elongation factor 2 (EFT1) and D-arabinose dehydrogenase [NAD (P)+] heavy chain (ARA1) (Table 2). The most abundant protein, HSP12, had a notable abundance ratio compared to all the other matched proteins (Table 2). However, GAP1 cocrystallized during storage before LC-MS/MS analysis, so the abundance ratio of GAP1 in the total released proteins was underestimated.

Potential strong promoters under lactate culture conditions. High abundance of proteins in culture medium may be a result of $\mathrm{pH}$-induced expression, protein stability, or both. To further investigate the transcription levels of the matched protein-encoding genes, the expression of the HSP12, GAP1, and ENO genes was measured by using quantitative real-time polymerase chain reaction (qPCR) after $120 \mathrm{~h}$ of culture (Fig. 4). In addition, the potential promoters of INU1 and PGU1, which encode inulinase and polygalacturonase, respectively, were also analyzed. The promoter of INU1 was applied for heterologous protein expression ${ }^{16,17}$, and the promoter of $P G U 1$ has potential biotechnological applications in $K$. marxianus ${ }^{18}$. The transcription levels of all the genes were determined by qPCR and compared with that of the actin $(A C T)$ gene to calculate the relative transcription levels. HSP12 presented relatively high transcription levels at $\mathrm{pH} 3.9$ and $\mathrm{pH} 4.8$, and the transcription level decreased at $\mathrm{pH} 5.44$ and $\mathrm{pH} 6.23$ (Fig. 4). The GAP1 transcription level was lower than that of $A C T$ under all the tested conditions (Fig. 4). ENO transcription was high at $\mathrm{pH} 3.9$ but decreased at $\mathrm{pH} 4.8, \mathrm{pH}$ 5.44 and $\mathrm{pH} 6.23$ (Fig. 4). The notably high transcription levels of PGU1 at every tested pH except at pH 5.44 indicated the potential for application in heterologous enzyme expression. On the other hand, the transcription levels of INU1 were lower than those of PGU1 except at pH 5.44 (Fig. 4). 


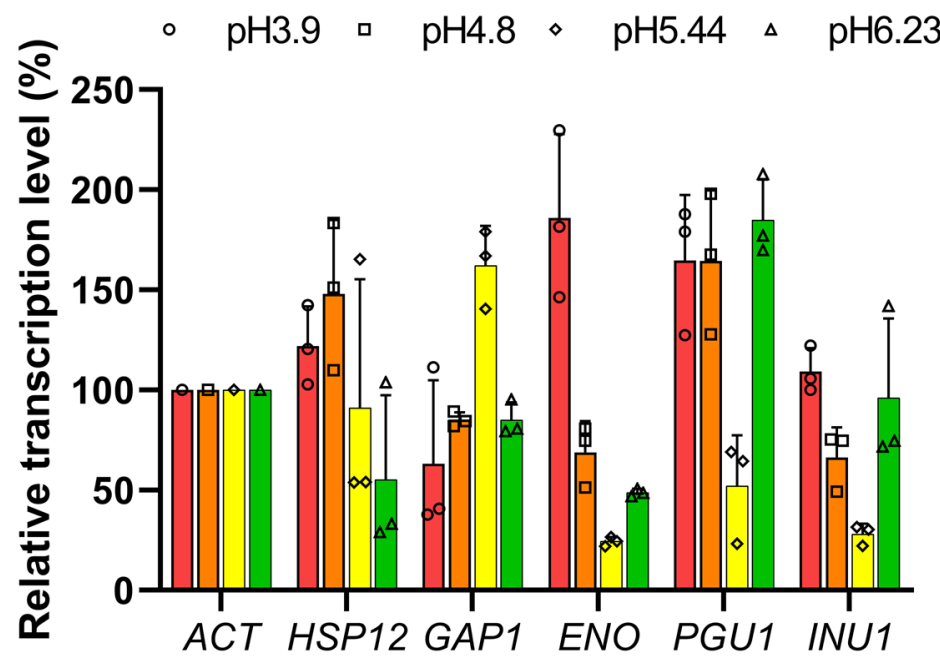

Figure 4. Relative transcription levels of HSP12, GAP1, ENO, PGU1, and INU1 compared with those of ACT at $\mathrm{pH} 3.9, \mathrm{pH} 4.8, \mathrm{pH} 5.44$, and $\mathrm{pH} 6.23$ in culture. The data are presented as the mean and standard deviation of three replicates. This image was created by using GraphPad Prism (version 8.2.1; https://www.graphpad.com/ scientific-software/prism/).

\section{Discussion}

Kluyveromyces marxianus exhibits various phenotypes among strains, therefore it is important to classify the newly isolated strain at least on the genetic level for further study ${ }^{11}$. The strain most closely related to K. marxianus Bot $3+7$ was identified as K. marxianus CCT 7735 (Supplementary Fig. S1). Both strains were isolated from dairy sources and may have similar phenotypes, as discovered in this study. Lactate is the primary acid that is produced in kefir culture, and its level can range from 0.6 to $1 \%(\mathrm{w} / \mathrm{v})^{19,20}$. On the other hand, application of the lactate assimilation trait of $K$. marxianus was reported to reduce the L-lactate feedback inhibition of Lactococcus lactis for nisin production ${ }^{7}$. This indicates that K. marxianus could play the same role during kefir production and the potential of lactate usage for biotechnological applications. In this study, we focused on using lactate as the sole carbon source to culture K. marxianus. The proteins released from K. marxianus under lactate culture conditions were identified.

DL-lactate was used as the sole carbon substrate for batch cultivation of $K$. marxianus at different $\mathrm{pH}$ values. Even under the optimal growth conditions at $\mathrm{pH} 4.18$, as shown in the results (Table 1), the released protein concentrations and the SDS-PAGE analysis of released protein indicated that some of the yeast cells were still autolyzed (Supplementary Fig. S7). The mechanism of autolysis in K. marxianus is similar to the mechanism in S. cerevisia $e^{21,22}$, which is based on the biosynthesis of lytic enzymes, and optimum autolysis was observed at $\mathrm{pH}$ 4.5 in culture ${ }^{22}$. In this study, the optimum culture $\mathrm{pH}$ for autolysis was observed to be $\mathrm{pH} 5.2$ (Table 1). However, the culture conditions were different from those in this study ${ }^{22}$, since this work lacked fermentable carbon sources in the culture medium. In the presence of $0.2 \mathrm{M} \mathrm{MgCl}_{2}$, the final cell concentrations and the released protein concentrations in the culture medium increased and decreased, respectively (Fig. 1c,d). The presence of excess $\mathrm{Mg}^{2+}$ ions facilitates protein secretion in $K$. marxianus $\left(0.2 \mathrm{M} \mathrm{MgSO}_{4}\right)^{13}$ and decreases autolysis in marine bacteria $\left(0.5 \mathrm{M} \mathrm{MgCl}_{2}\right)$ and $S$. cerevisiae $\left(0.1 \% \mathrm{MgCl}_{2}\right)^{14,23}$. Although the mechanism remains unclear, it was proposed that $\mathrm{Mg}^{2+}$ ions might help organize cell membranes in both eukaryotes and prokaryotes ${ }^{13}$. The GAP1 and HSP12 proteins found in the culture filtrate were also related to the maintenance of cell membrane integrity and stability ${ }^{24,25}$. These results suggest that $K$. marxianus may bear the stress that could decompose membranes. Nonetheless, the inhibition of autolysis suggested that the presence of $0.2 \mathrm{M} \mathrm{MgCl}_{2}$ helped K. marxianus resist the stress occurring under the lactate culture conditions (Fig. 1c,d).

LC-MS/MS analysis of the total protein content revealed the identities of the proteins released during and after autolysis, other than the cocrystallized GAP1, and it also provided a glimpse of the metabolic pathways in K. marxianus. Enzymes in central metabolic pathways, such as the tricarboxylic acid cycle, glycolysis/gluconeogenesis, and pentose phosphate pathway, were identified (Supplementary Tables S2-S4). Although DL-lactate was the only carbon source that was supplied to the culture medium, proteins related to galactose and inulin metabolism were also expressed (Supplementary Tables S2-S4). These results suggest that K. marxianus has the potential to assimilate galactose and inulin under these culture conditions. Four lactate metabolism-related proteins, namely, carboxylic acid transporter, D-lactate dehydrogenase, D-lactate dehydrogenase 2 and cytochrome b2, were identified (Supplementary Table S2). D-lactate dehydrogenase [cytochrome] catalyzes the conversion of D-lactate to pyruvate with the reduction of two molecules of cytochrome. The association between these identified lactate assimilation proteins and the expression of the central metabolism enzymes indicates the lactate assimilation pathway in K. marxianus. It was reported that the PGU1 promoter is activated in the presence of lactate in S. cerevisiae ${ }^{6}$. In the lactate culture of $K$. marxianus, the transcription level of $P G U 1$ was higher than that of GAP1 but lower than that of INU1 at pH 5.44 (Fig. 4). However, none of the analyzed peptides matched the PGU1 protein in our results. Among the 15 most abundant proteins in the 288 -h culture medium, the average 
emPAI\% of HSP12 was $18.7 \%$, and that of the second abundant protein, GAP1, was $3.51 \%$ (Table 2). There was a $15.19 \%$ difference between these two proteins, and the third most abundant protein differed from GAP1 by only $1.21 \%$ (Table 2). These results suggest that most of the proteins were digested to unidentified peptides under the autolysis conditions. Therefore, PGU1 might be digested to unidentified peptides. However, none of the peptides matched PGU1, even though no enzyme digest fingerprints were considered (data not shown), which needs to be further investigated.

GAP1 was cocrystallized in the cell-free fraction and was found to be a relatively high abundance protein in the results at pH 5.44 in the 288-h culture medium (3.51 emPAI\%) and 120-h pellets (2.32 emPAI\%) (Table 2). On the other hand, actin exhibited only $0.191 \mathrm{emPAI} \%$ in the 120 -h pellets (Supplementary Dataset). However, the transcription level of GAP1 was lower than that of ACT (Fig. 4). These results suggest that the protein abundance under the autolysis condition was dependent on the stability of the protein, not on the gene transcription level. The most abundant protein, HSP12, was reported to increase membrane stability under different stress conditions in S. cerevisiae, such as heat shock and oxidative and osmotic stresses ${ }^{25}$. The expression of HSP12 in S. cerevisiae may also contribute to lifespan extension by protecting the membrane from desiccation ${ }^{26,27}$. The relatively high expression of HSP12 (Fig. 4) under the autolysis conditions suggests that HSP12 might play a similar role in protecting $K$. marxianus cells.

Protein abundance was related to protein stability and to K. marxianus abundance under the autolysis conditions. However, one cannot exclude the possibility that proteins might also be secreted into the medium rather than released from dead yeast cells. For example, GAP1, enolase and pyruvate decarboxylase are secreted into the extracellular space in Candida albicans without $\mathrm{N}$-terminal signal peptides ${ }^{28}$. These nonconventional protein secretion pathways were also found in S. cerevisiae ${ }^{29}$ and are related to nonclassical export (NCE) genes ${ }^{30}$ such as $^{2}$ NCE102, which is also encoded in the K. marxianus genome ${ }^{31}$. In our results, while most of the GAP1 was in the cell pellet, most of the enolase was already in the culture medium at $120 \mathrm{~h}$ (Table 2). These findings suggest that nonconventional protein secretion occurred under lactate culture conditions. Therefore, the secreted proteins might also be digested to peptides as the rest of the proteins are released by autolysis and become substrates for other symbiosis-related proteins in kefir. The well-known symbiotic interaction between Lactobacillus bulgaricus and Streptococcus thermophilus in yogurt is that S. thermophilus produces formate to stimulate L. bulgaricus, and L. bulgaricus liberates free amino acids and peptides from milk proteins to stimulate $S$. thermophilus ${ }^{32}$. In this study, lactate was used as a substrate for $K$. marxianus growth and induced autolysis of $K$. marxianus to release proteins and peptides into the cell-free fraction. This suggests that the lactate produced by lactic acid bacteria would induce the release of proteins and peptides from K. marxianus. However, the functions of these proteins and peptides remain to be discovered by coculturing $K$. marxianus with lactic acid bacteria.

Kluyveromyces marxianus has received recognition for its potential industrial applications in recent years due to its thermotolerance, rapid growth rates, and broad substrate spectrum ${ }^{33}$. Although knowledge of its biochemistry and genetics is limited compared to that for S. cerevisiae, many studies based on different biochemical principles, such as nonhomologous end joining ${ }^{34}$, homologous recombination ${ }^{35,36}$, and the CRISPR/Cas9 mechanism ${ }^{37}$, have been applied to develop genetic engineering tools. These studies used fermentable substrates for culture, such as glucose and galactose. Therefore, knowledge on culturing nonfermentable substrates is limited. In this study, the optimal lactate culture conditions, the released proteins and the transcription levels of several genes were determined in K. marxianus. Autolysis occurred in all of the experimental lactate culture conditions, and the LC-MS/MS results including various heat shock proteins could be the foundation for $K$. marxianus probiotic and kefir research.

\section{Materials and methods}

Yeast strain and culture conditions. The K. marxianus Bot $3+7$ strain was isolated from homemade kefir in Taiwan. The yeast was first precultured for 2 days at $30^{\circ} \mathrm{C}$ with rotation at $120 \mathrm{rpm}$ in YPD medium containing $10 \mathrm{~g}$ of yeast extract, $20 \mathrm{~g}$ of peptone, and $20 \mathrm{~g}$ of glucose per liter of distilled water. To measure growth and protein release, precultured cells from a two-day culture were diluted 1:100 by adding $30 \mu \mathrm{L}$ of the suspension to $3 \mathrm{~mL}$ of YNL medium (a synthetic medium composed of $6.7 \mathrm{~g}$ of yeast nitrogen-base without amino acids (Difco, Detroit, MI, USA) and $20 \mathrm{~g}$ of lactic acid (J.T. Baker, Philipsburg, NJ, USA) per liter of distilled water) or YNGlycerol medium (a synthetic medium composed of $6.7 \mathrm{~g}$ of yeast nitrogen-base without amino acids (Difco, Detroit, MI, USA) and $16 \mathrm{~g}$ of glycerol (Union Chemical Works, Hsinchu City, Taiwan) per liter of distilled water). The $\mathrm{pH}$ of the medium was adjusted by the addition of $\mathrm{NaOH}$ (Showa, Tokyo, Japan). All yeast cultures were incubated at $30^{\circ} \mathrm{C}$ in a rotating incubator $(120 \mathrm{rpm})$. The medium was supplemented with $\mathrm{MgCl}_{2}$ as indicated in the manuscript. To determine cell viability, the colony-forming unit (CFU) method was used. The yeast cells in culture medium were suspended in sterile water and diluted to a final concentration of about $10^{3}$ cells/ $\mathrm{mL}$. A $150 \mu \mathrm{L}$ sample of the suspension was inoculated on solid YPD medium and incubated at $37^{\circ} \mathrm{C}$. The CFUs were counted after $48 \mathrm{~h}$ of incubation. For LC-MS/MS analysis of the total protein content, the precultured cells were diluted by adding $3 \mathrm{~mL}$ of the suspension to $300 \mathrm{~mL}$ of YNL medium (pH 5.44) and incubated at $30^{\circ} \mathrm{C}$ in a shaking incubator (120 rpm) for LC-MS/MS protein analysis.

Multilocus sequence typing. The genomic DNA of yeast was extracted with the FavorPrep Fungi/Yeast Genomic DNA Extraction Mini Kit (Favorgen, Taiwan) according to the manufacturer's instructions. The DNA yield was determined by a Nano-100 Micro-Spectrophotometer (Medclub Scientific Co., Ltd., Taiwan). A total of $10 \mathrm{ng}$ of genomic DNA was used in a $25 \mu \mathrm{L}$ polymerase chain reaction (Phusion High-Fidelity DNA Polymerase, New England Biolabs, USA). The PCR conditions were as follows: initial denaturation at $98^{\circ} \mathrm{C} \mathrm{for} 50 \mathrm{~s}$; followed by 35 cycles of denaturation at $98^{\circ} \mathrm{C}$ for $30 \mathrm{~s}$, annealing at $62{ }^{\circ} \mathrm{C}$ for $30 \mathrm{~s}$ and elongation at $72{ }^{\circ} \mathrm{C}$ for $1 \mathrm{~min}$; followed by a final extension step at $72{ }^{\circ} \mathrm{C}$ for $7 \mathrm{~min}$. The amplified DNA products were separated in a $0.8 \%(\mathrm{w} / \mathrm{v})$ 
agarose gel in $0.5 \times$ TAE buffer ( $20 \mathrm{mM}$ Tris, $10 \mathrm{mM}$ acetic acid, $0.6 \mathrm{mM}$ EDTA) at $50 \mathrm{~V}$ for $1 \mathrm{~h}$, stained with SafeView (BioPioneer, Taiwan) and visualized with a LED transilluminator (BV 200, Clinx Science Instruments, China). The DNA bands were excised from the gels and sequenced in each direction by Genomics (Taiwan). The sequences were prepared as a multi fasta file by following the instructions on the $K$. marxianus MLST analysis website $^{11}$. The phylogenetic tree was generated with the Interactive Tree Of Life online tool (version 6.0) under free access mode (itol.embl.de) ${ }^{38}$. All the primers used for analysis in this study are listed in Supplementary Table S5.

Growth curves and protein concentration determination. The growth of the K. marxianus Bot $3+7$ strain was determined by measuring the $\mathrm{OD}_{600}$ and $\mathrm{OD}_{595}$ with a GeneQuant 1300 system (GE Healthcare, Little Chalfont, Buckinghamshire, UK) and a Tecan Sunrise Basic microplate reader (Tecan Austria GmbH, Grödig, Austria), respectively. At each time point during the 5 -day cultivation period, $20 \mu \mathrm{L}$ of yeast culture was sampled and aliquoted into a 96-well microplate in triplicate and diluted 1:10 by adding $180 \mu \mathrm{L}$ of distilled water to measure the growth. Additionally, protein secretion into the external medium was determined by measuring the $\mathrm{OD}_{595}$ with a Tecan Sunrise Basic microplate reader using the Bradford method with bovine serum albumin as the standard by following the manufacturer's instructions (Bio-Rad Protein Assay Dye Reagent, Bio-Rad, Hercules, CA, USA). For this, $50 \mu \mathrm{L}$ of yeast culture at each time point was centrifuged at $14,000 \mathrm{rpm}$ for $3 \mathrm{~min}$. After centrifugation, $40 \mu \mathrm{L}$ of supernatant was sampled into a 96-well microplate in triplicate, and $160 \mu \mathrm{L}$ of Bradford reagent $(1.25$-fold) was added to be diluted fivefold with the protein.

High performance liquid chromatography (HPLC) analysis. The culture media of the samples were treated with $10 \%$ trichloroacetic acid and incubated on ice for $30 \mathrm{~min}$. The supernatants were collected by centrifugation at $14,000 \mathrm{rpm}$ at $4{ }^{\circ} \mathrm{C}$ for $15 \mathrm{~min}$ and followed by HPLC analysis. The concentrations of lactic acid and glycerol were determined by KNAUER PLATINblue UHPLC System (KNAUER, Berlin, Germany) equipped with an HPLC column Shodex SH1011 (particle size $6 \mu \mathrm{m}, 300 \mathrm{~mm} \times 8 \mathrm{~mm}$, Showa Denko America, New York, NY, USA) and a refractive index (RI) detector (AZURA RID 2.1L, KNAUER, Berlin, Germany). The mobile phase was $5 \mathrm{mM} \mathrm{H}_{2} \mathrm{SO}_{4}$, and the flow rate was $0.6 \mathrm{~mL} / \mathrm{min}$. The column temperature was at $60^{\circ} \mathrm{C}$. The injection volume was $10 \mu \mathrm{L}$ for each analysis.

SDS-PAGE. The crystals were collected into $1.5-\mathrm{mL}$ centrifuge tubes with pipet tips and washed with $\mathrm{dd}_{2} \mathrm{O}$. Then, the crystals were added and dissolved into Bradford reagent solutions until saturation. Ten microliters of sample and prestained protein marker (PageRuler Plus Prestained Protein Ladder, 10 to $250 \mathrm{kDa}$, Thermo Scientific) were used for SDS-PAGE analysis.

Sample preparation for LC-MS/MS protein analysis. Proteins in the SDS-PAGE gel. The protein bands were first excised as small pieces from the gel. Then, $25 \mathrm{mM}$ ammonium bicarbonate (ABC, Fluka) (dissolved in 50\% acetonitrile (ACN, J.T. Baker, Philipsburg, NJ, USA)) was added. The mixture was incubated for $30 \mathrm{~min}$ at room temperature, which was repeated if the gel pieces were not destained. Dehydration was performed by the addition of $100 \%$ ACN. Reduction and alkylation were performed with the following steps: $10 \mathrm{mM}$ dithiothreitol (DTT, Sigma) (dissolved in $50 \mathrm{mM} \mathrm{ABC}$ ) was added to the gel pieces, followed by incubation for $60 \mathrm{~min}$ at $56^{\circ} \mathrm{C}$. The solutions were discarded, $55 \mathrm{mM}$ iodoacetamide (IAA, dissolved in $50 \mathrm{mM} \mathrm{ABC}$; Sigma) was added, and the gel pieces were incubated for $45 \mathrm{~min}$ in the dark at room temperature. The solutions were discarded, and the gel pieces were dehydrated with $100 \%$ ACN. Trypsin $(12.5 \mathrm{ng} / \mu \mathrm{L}$, dissolved in $50 \mathrm{mM}$ $\mathrm{ABC}$; Trypsin Gold, Promega) was added to the gel pieces, which were rehydrated at $4{ }^{\circ} \mathrm{C}$ for $30-60 \mathrm{~min}$ and then digested overnight at $37^{\circ} \mathrm{C}$. To recover the peptides from the gel, first, $30-100 \mu \mathrm{L}$ of $5 \%$ formic acid (FA, dissolved in 50\% ACN; Fluka) was added, and the gel pieces were agitated at room temperature for 30-60 min and transferred to a new centrifuge tube. Second, $15-50 \mu \mathrm{L}$ of $5 \% \mathrm{FA}$ was added, and the tube was incubated at room temperature for $10 \mathrm{~min}$, followed by the addition of $15-50 \mu \mathrm{L}$ of $100 \% \mathrm{ACN}$ and agitation for 30-60 min. Third, the two extract solutions were combined and dried in a Speed Vac. The samples were desalted using C18 ZipTips (Millipore) with the following steps: the dried peptide mixtures were desalted in $10 \mu \mathrm{L}$ of $\mathrm{ddH}_{2} \mathrm{O}$ containing $0.1 \%$ FA, a ZipTip was activated by rinsing 3 times with $10 \mu \mathrm{L}$ of $100 \%$ ACN, the tip was equilibrated 3 times with $10 \mu \mathrm{L}$ of $0.1 \%$ FA, peptides were bound to the tip by aspirating and dispensing the peptide solutions 10 times, the tip was washed 6 times with $10 \mu \mathrm{L}$ of $0.1 \% \mathrm{FA}$, and peptides were eluted with $10 \mu \mathrm{L}$ of $0.1 \%$ FA (dissolved in $50 \% \mathrm{ACN}$ ) by aspirating and dispensing 10 times. These steps were repeated to obtain a combined solution, and the combined solution was dried with a SpeedVac vacuum concentrator.

Proteins in cell pellets and autolysis medium. The cell pellets of the 120-h samples were collected and washed eight times with $40 \mathrm{~mL}$ of $50 \mathrm{mM}$ Tris- $\mathrm{HCl}\left(\mathrm{pH} \mathrm{8.03)}\right.$ at $16^{\circ} \mathrm{C}$. The washed pellets were dissolved in $1 \mathrm{~mL}$ of $50 \mathrm{mM}$ Tris- $\mathrm{HCl}$ (pH 8.03), and approximately $300 \mu \mathrm{L}$ of $0.5 \mathrm{~mm}$ glass beads was added. The glass beads and pellet mixture were vortexed in a cyclomixer 30 times at $2500 \mathrm{rpm}$ for $30 \mathrm{~s}$ each, immersing the cell suspension in ice for $30 \mathrm{~s}$ between vortexing cycles to obtain at least $3 \mu \mathrm{g} / \mu \mathrm{L}$ protein. The proteins in the supernatant of the 120 -h and 288-h K. marxianus cultures were concentrated to at least $3 \mu \mathrm{g} / \mu \mathrm{L}$ using Amicon Ultra- $153 \mathrm{k}$ molecular weight cutoff membranes (Millipore) according to the manufacturer's instructions. The autolysis medium samples were also dialyzed $3.7 \times 10^{-15}$ times with $50 \mathrm{mM}$ Tris- $\mathrm{HCl}(\mathrm{pH} 8.03)$. Then, $1 \mu \mathrm{L}$ of DTT (1 M) and $2.5 \mu \mathrm{L}$ of $10 \%$ SDS were added to $20 \mu \mathrm{L}$ of the samples, and the samples were cooled to room temperature after incubation for $10 \mathrm{~min}$ at $95^{\circ} \mathrm{C}$. Three microliters of $1 \mathrm{M} \mathrm{IAA}$ was added, and the samples were reacted for $30 \mathrm{~min}$ in the dark at room temperature. Twelve microliters of $40 \%$ acrylamide, $4.5 \mu \mathrm{L}$ of $10 \%$ SDS, $1.5 \mu \mathrm{L}$ of $10 \%$ APS and $0.5 \mu \mathrm{L}$ of TEMED were added, and the samples were incubated for $30 \mathrm{~min}$ at room temperature to form a 
tube gel. The solutions were discarded, and $500 \mu \mathrm{L}$ of $\mathrm{ddH}_{2} \mathrm{O}$ was added. Then, the gel was incubated for $30 \mathrm{~min}$ at room temperature and cut into small pieces. The small pieces were washed three times. First, $100 \mathrm{mM} \mathrm{ABC}$ was used for $15 \mathrm{~min}$. Then, $50 \mathrm{mM} \mathrm{ABC}$ and $50 \%$ ACN were used for $30 \mathrm{~min}$, followed by washing with $100 \%$ $\mathrm{ACN}$ for $10 \mathrm{~min}$. After washing, the samples were dried with a SpeedVac vacuum concentrator. Trypsin $(0.5 \mu \mathrm{g})$ was added, and the samples were digested at $37^{\circ} \mathrm{C}$ for $16 \mathrm{~h}$. ACN $(100 \%)$ was added to the peptide extract and reacted for $30 \mathrm{~min}$ at room temperature, and then, the supernatant was transferred to a new tube. ACN (50\%) and FA (1\%) were added, and the samples were incubated for $60 \mathrm{~min}$ at room temperature. Then, the supernatant was transferred to a new tube. Subsequently, $100 \% \mathrm{ACN}$ was added, and the samples were incubated for $10 \mathrm{~min}$ at room temperature. Then, the supernatant was transferred to a new tube. The supernatant was dried with a SpeedVac vacuum concentrator and resuspended in $20 \mu \mathrm{L}$ of $0.1 \%$ FA (in $\mathrm{ddH}_{2} \mathrm{O}$ ). The samples were desalted and concentrated using C18 ZipTip as mentioned previously. The samples were then resuspended in $50 \mu \mathrm{L}$ of $0.1 \%$ FA (in $\mathrm{ddH}_{2} \mathrm{O}$ ).

LC-MS/MS protein analysis. LC-MS/MS analysis was performed on an UltiMate 3000 RSLCnano LC system (Thermo Fisher Scientific) coupled with a TripleTOF 6600 mass spectrometer (Applied Biosystems Sciex) equipped with information-dependent acquisition (IDA) mode and an electrospray ionization (ESI) source operating in positive mode.

Protein identification. The proteins in the SDS-PAGE gel were identified by using the following methods. The liquid chromatography conditions were as follows: separation of eluted peptides was performed on an Acclaim PepMap C18 analytical column (75 $\mu$ m I.D. $\times 25 \mathrm{~cm}$ nanoViper, $2 \mu \mathrm{m}$ particle size, $100 \AA$ pore size, Thermo Fisher Scientific). Mobile phase A was $0.1 \%$ FA in $\mathrm{ddH}_{2} \mathrm{O}$, and mobile phase B was $0.1 \%$ FA in $100 \%$ ACN. The gradient was as follows: $0-4.5 \mathrm{~min} 95 \% \mathrm{~A}, 4.5-31 \mathrm{~min} 95-65 \% \mathrm{~A}, 31-32 \mathrm{~min} 65-10 \% \mathrm{~A}, 32-52 \mathrm{~min} 10 \% \mathrm{~A}$, 52-53 $\mathrm{min} 10-95 \% \mathrm{~A}$, and $53-70 \mathrm{~min} 95 \% \mathrm{~A}$. The flow rate was $300 \mathrm{~nL} / \mathrm{min}$ at $35^{\circ} \mathrm{C}$, and the sample loading volume was $10 \mu \mathrm{L}(0.1 \% \mathrm{FA})$. The samples were examined in triplicate.

The mass spectrometric conditions were as follows: The operating parameters of ESI mode were utilized: ion spray voltage $+2500 \mathrm{~V}$, interface heater temperature $150{ }^{\circ} \mathrm{C}$, declustering potential $80 \mathrm{~V}$ and column oven temperature $35^{\circ} \mathrm{C}$. The sheath gas and curtain gas were both nitrogen, and the pressures were 15 and $30 \mathrm{psi}$, respectively. The IDA mode was utilized. The TOF-MS scan range was set to $350-1250 \mathrm{~m} / \mathrm{z}$ acclimated for $0.25 \mathrm{~s}$, and the MS/MS scan range was set to $65-1800 \mathrm{~m} / \mathrm{z}$ acclimated for $0.1 \mathrm{~s}$. Rolling collision energy voltage was used. The top 20 parent ions were selected following MS/MS. Mascot (version 2.3.02) was used to search the database.

Proteomics identifications (PRIDE). The released proteins were identified by the methods described above. Under LC conditions, the gradient was as follows: 0-4.5 min 95\% A, 4.5-95 min 95-70\% A, 95-101 min 70-40\% A, $101-106 \min 40-10 \%$ A, $106-131$ min $10 \%$ A, $131-132 \min 10-95 \%$ A, and $132-150$ min $95 \%$ A. The flow rate was $300 \mathrm{~nL} / \mathrm{min}$ at $35^{\circ} \mathrm{C}$, and the sample loading volume was $10 \mu \mathrm{L}(0.1 \% \mathrm{FA})$.

The mass spectrometric conditions were as follows: The operating parameters of ESI mode were utilized: ion spray voltage $+2800 \mathrm{~V}$, interface heater temperature $150^{\circ} \mathrm{C}$, declustering potential $80 \mathrm{~V}$, column oven temperature $35^{\circ} \mathrm{C}$. The sheath gas and curtain gas were both nitrogen, and the pressures were 15 and $30 \mathrm{psi}$, respectively. The IDA mode was utilized. The TOF-MS scan range was set to $350-1250 \mathrm{~m} / \mathrm{z}$ acclimated for $0.25 \mathrm{~s}$, and the MS/ MS scan range was set to $65-1800 \mathrm{~m} / \mathrm{z}$ acclimated for $0.1 \mathrm{~s}$. Rolling collision energy voltage was used. The top 20 parent ions were selected following MS/MS. Mascot (version 2.3.02) was used to search the database.

Mascot search parameters. The type of search and enzyme were set as MS/MS Ion Search and trypsin, respectively. The variable modifications included carbamidomethyl (C), deamidated (NQ), oxidation (HW), and oxidation (M). Monoisotopic was used as the mass parameter, and the mass tolerance values for peptides and fragments were $\pm 0.05 \mathrm{Da}$ and $\pm 0.03 \mathrm{Da}$, respectively. The max missed cleavages by enzyme was set as 2 . The database used for the search was the NCBI K. marxianus database. The results are provided as a Supplementary Dataset.

Quantitative real time polymerase chain reaction procedure. Total RNA extraction was performed using TRIzol Reagent (Invitrogen). The yeast cells were collected by centrifugation, and then, the total RNA was extracted according to the manufacturer's instructions. The RNA yield was determined by a Nano-100 MicroSpectrophotometer (Medclub Scientific Co., Ltd., Taiwan). A total of $0.1 \mu \mathrm{g}$ of RNA was converted to cDNA using the GoScript ${ }^{\text {th }}$ Reverse Transcription System, and qPCR analysis was performed using LightCycler 480 SYBR Green Master Mix (Roche) on a Rotor-Gene 3000 Real-Time DNA Detection System (Corbett Research). The transcription levels were calculated for reverse transcriptase-treated and nontreated samples and normalized to those of actin $(A C T)$. The changes in relative transcription levels were calculated as fold changes using the $\Delta \Delta \mathrm{Ct}$ method. All the primers used for analysis in this study are listed in Supplementary Table S5.

\section{Data availability}

All data generated or analyzed during this study are included in this published article (and its Supplementary Information files).

Received: 8 January 2021; Accepted: 6 July 2021

Published online: 15 July 2021 


\section{References}

1. Prado, M. R. et al. Milk kefir: Composition, microbial cultures, biological activities, and related products. Front. Microbiol. https:// doi.org/10.3389/fmicb.2015.01177 (2015).

2. Gethins, L. et al. Acquisition of the yeast Kluyveromyces marxianus from unpasteurised milk by a kefir grain enhances kefir quality. FEMS Microbiol. Lett. 363, 165. https://doi.org/10.1093/femsle/fnw165 (2016).

3. Aziz, H.-R., Aslan, A., Parvin, O. \& Hadi, P. Kluyveromyces marxianus as a probiotic yeast: A mini-review. Curr. Nutr. Food Sci. 16, 1163-1169. https://doi.org/10.2174/1573401316666200217113230 (2020).

4. Ha-Tran, D. M., Nguyen, T. T. M. \& Huang, C.-C. Kluyveromyces marxianus: Current state of omics studies, strain improvement strategy and potential industrial implementation. Fermentation 6, 124 (2020).

5. Wang, J. et al. Cell wall polysaccharides: Before and after autolysis of brewer's yeast. World J. Microbiol. Biotechnol. 34, 137. https:// doi.org/10.1007/s11274-018-2508-6 (2018).

6. Gognies, S., Simon, G. \& Belarbi, A. Regulation of the expression of endopolygalacturonase gene PGU1 in Saccharomyces. Yeast 18, 423-432. https://doi.org/10.1002/yea.693 (2001).

7. Shimizu, H., Cheirsilp, B. \& Shioya, S. Development of co-culture systems of lactic acid bacteria and yeasts for bioproduction. Jpn. J. Lactic Acid Bacteria 16, 2-10. https://doi.org/10.4109/jslab1997.16.2 (2005).

8. Fonseca, A., Spencer-Martins, I. \& Van Uden, N. Transport of lactic acid in Kluyveromyces marxianus: Evidence for a monocarboxylate uniport. Yeast 7, 775-780. https://doi.org/10.1002/yea.320070803 (1991).

9. Alexandre, H. \& Guilloux-Benatier, M. Yeast autolysis in sparkling wine-A review. Aust. J. Grape Wine Res. 12, 119-127. https:// doi.org/10.1111/j.1755-0238.2006.tb00051.x (2006).

10. Marchal, A., Marullo, P., Durand, C., Moine, V. \& Dubourdieu, D. Fermentative conditions modulating sweetness in dry wines: Genetics and environmental factors influencing the expression level of the Saccharomyces cerevisiae HSP12 gene. J. Agric. Food Chem. 63, 304-311. https://doi.org/10.1021/jf504408t (2015).

11. Tittarelli, F. et al. Development and implementation of multilocus sequence typing to study the diversity of the yeast Kluyveromyces marxianus in Italian cheeses. Microbial Genomics 4, e000153. https://doi.org/10.1099/mgen.0.000153 (2018).

12. Silveira, W. B. et al. Genomic sequence of the yeast Kluyveromyces marxianus CCT 7735 (UFV-3), a highly lactose-fermenting yeast isolated from the Brazilian dairy industry. Genome Announc. 2, e01136-e1114. https://doi.org/10.1128/genomeA.01136-14 (2014).

13. Nambu-Nishida, Y., Nishida, K., Hasunuma, T. \& Kondo, A. Genetic and physiological basis for antibody production by Kluyveromyces marxianus. AMB Express 8, 56-56. https://doi.org/10.1186/s13568-018-0588-1 (2018).

14. Dabija, A. \& Sion, I. SIPA' 03 51-56 (Orizonturi Universitare, 2003).

15. Ishihama, Y. et al. Exponentially modified protein abundance index (emPAI) for estimation of absolute protein amount in proteomics by the number of sequenced peptides per protein. Mol. Cell. Proteomics 4, 1265-1272. https://doi.org/10.1074/mcp.M5000 61-MCP200 (2005).

16. Bergkamp, R. J. et al. Expression of an alpha-galactosidase gene under control of the homologous inulinase promoter in Kluyveromyces marxianus. Appl. Microbiol. Biotechnol. 40, 309-317. https://doi.org/10.1007/bf00170386 (1993).

17. Rocha, S. N., Abrahão-Neto, J., Cerdán, M. E., Gombert, A. K. \& González-Siso, M. I. Heterologous expression of a thermophilic esterase in Kluyveromyces yeasts. Appl. Microbiol. Biotechnol. 89, 375-385. https://doi.org/10.1007/s00253-010-2869-8 (2011).

18. Piemolini-Barreto, L. T., AntÔnio, R. V. \& Echeverrigaray, S. Screening and breeding of Kluyveromyces strains for production pectinolytic activity. Adv. Biotechnol. Microbiol. 3, 555608. https://doi.org/10.19080/AIBM.2017.03.555608 (2017).

19. Guzel-Seydim, Z., Seydim, A. C. \& Greene, A. K. Organic acids and volatile flavor components evolved during refrigerated storage of kefir. J. Dairy Sci. 83, 275-277. https://doi.org/10.3168/jds.S0022-0302(00)74874-0 (2000).

20. Özdestan, Ö. \& Üren, A. Biogenic amine content of kefir: A fermented dairy product. Eur. Food Res. Technol. 231, 101-107. https:// doi.org/10.1007/s00217-010-1258-y (2010).

21. Amrane, A. \& Prigent, Y. Behaviour of the yeast Kluyveromyces marxianus var. marxianus during its autolysis. Antonie Van Leeuw. 69, 267-272. https://doi.org/10.1007/BF00399615 (1996)

22. Amrane, A. \& Prigent, Y. Effect of culture conditions of Kluyveromyces marxianus on its autolysis, and process optimization. Bioprocess. Eng. 18, 383-388. https://doi.org/10.1007/PL00008998 (1998).

23. Sugahara, I., Hayashi, K., Kimura, T. \& Jinno, C. Studies on marine bacteria producing lytic enzymes-IX: Effect of inorganic salts on the autolysis of bacterial cells capable of producing lytic enzyme (1983).

24. Falcão Moreira, R., Fernandes, P. A. \& Moradas-Ferreira, P. Kluyveromyces marxianus flocculence and growth at high temperature is dependent on the presence of the protein p37. Microbiology 144, 681-688. https://doi.org/10.1099/00221287-144-3-681 (1998).

25. Welker, S. et al. Hsp12 is an intrinsically unstructured stress protein that folds upon membrane association and modulates membrane function. Mol. Cell 39, 507-520. https://doi.org/10.1016/j.molcel.2010.08.001 (2010).

26. Herbert, A. P. et al. NMR structure of Hsp12, a protein induced by and required for dietary restriction-induced lifespan extension in yeast. PLoS ONE 7, e41975. https://doi.org/10.1371/journal.pone.0041975 (2012).

27. Singarapu, K. K. et al. Structural characterization of Hsp12, the heat shock protein from Saccharomyces cerevisiae, in aqueous solution where it is intrinsically disordered and in detergent micelles where it is locally a-helical. J. Biol. Chem. 286, 43447-43453. https://doi.org/10.1074/jbc.M111.306464 (2011).

28. Gil-Bona, A. et al. Proteomics unravels extracellular vesicles as carriers of classical cytoplasmic proteins in Candida albicans. J. Proteome Res. 14, 142-153. https://doi.org/10.1021/pr5007944 (2015).

29. Kuchler, K. Unusual routes of protein secretion: The easy way out. Trends Cell Biol. 3, 421-426. https://doi.org/10.1016/09628924(93)90030-5 (1993)

30. Nombela, C., Gil, C. \& Chaffin, W. L. Non-conventional protein secretionin yeast. Trends Microbiol. 14, 15-21. https://doi.org/10. 1016/j.tim.2005.11.009 (2006)

31. Lertwattanasakul, N. et al. Genetic basis of the highly efficient yeast Kluyveromyces marxianus: Complete genome sequence and transcriptome analyses. Biotechnol. Biofuels 8, 47. https://doi.org/10.1186/s13068-015-0227-x (2015).

32. Arioli, S. et al. Streptococcus thermophilus urease activity boosts Lactobacillus delbrueckii subsp. bulgaricus homolactic fermentation. Int. J. Food Microbiol. 247, 55-64 (2017).

33. Fonseca, G. G., Heinzle, E., Wittmann, C. \& Gombert, A. K. The yeast Kluyveromyces marxianus and its biotechnological potential. Appl. Microbiol. Biotechnol. 79, 339-354. https://doi.org/10.1007/s00253-008-1458-6 (2008).

34. Hoshida, H. et al. Non-homologous end joining-mediated functional marker selection for DNA cloning in the yeast Kluyveromyces marxianus. Yeast 31, 29-46. https://doi.org/10.1002/yea.2993 (2014).

35. Chang, J.-J. et al. PGASO: A synthetic biology tool for engineering a cellulolytic yeast. Biotechnol. Biofuels 5, 53. https://doi.org/ 10.1186/1754-6834-5-53 (2012).

36. Nambu-Nishida, Y., Nishida, K., Hasunuma, T. \& Kondo, A. Development of a comprehensive set of tools for genome engineering in a cold- and thermo-tolerant Kluyveromyces marxianus yeast strain. Sci. Rep. 7, 8993. https://doi.org/10.1038/s41598-017-08356-5 (2017).

37. Rajkumar, A. S., Varela, J. A., Juergens, H., Daran, J.-M.G. \& Morrissey, J. P. Biological parts for Kluyveromyces marxianus synthetic biology. Front. Bioeng Biotechnol. https://doi.org/10.3389/fbioe.2019.00097 (2019). 
38. Letunic, I. \& Bork, P. Interactive tree of life (iTOL) v4: Recent updates and new developments. Nucleic Acids Res. 47, W256-W259. https://doi.org/10.1093/nar/gkz239 (2019).

\section{Acknowledgements}

We thank Ms. Chen Hui-Yi for technical support with LC-MS/MS analysis. The image in Fig. 2a was taken with an iPhone 6 (Camera app in iOS 12.5.1, Apple) through a microscope (Nikon) by S.C.L., and then, the image was edited by Adobe Photoshop 2020 by C.Y.Y. The image in Fig. 2 b was taken by an iPhone 6 (Camera app in iOS 12.5.1, Apple) by S.C.L., and then, the image was edited by Microsoft Office Professional 2019 PowerPoint by C.Y.Y. This work was supported by the Ministry of Science and Technology [107-2621-M-005-007-MY3 to C.C.H. and 108-2811-M-005-526- to S.C.L.].

\section{Author contributions}

S.C.L. conceived the experiments, S.C.L. and C.Y.Y. conducted the experiments, and S.C.L., C.Y.Y., D.C.M. and C.C.H. analyzed the results and wrote and reviewed the manuscript.

\section{Competing interests}

The authors declare no competing interests.

\section{Additional information}

Supplementary Information The online version contains supplementary material available at https:/doi.org/ 10.1038/s41598-021-94101-y.

Correspondence and requests for materials should be addressed to S.-C.L. or C.-C.H.

Reprints and permissions information is available at www.nature.com/reprints.

Publisher's note Springer Nature remains neutral with regard to jurisdictional claims in published maps and institutional affiliations.

(c) (i) Open Access This article is licensed under a Creative Commons Attribution 4.0 International License, which permits use, sharing, adaptation, distribution and reproduction in any medium or format, as long as you give appropriate credit to the original author(s) and the source, provide a link to the Creative Commons licence, and indicate if changes were made. The images or other third party material in this article are included in the article's Creative Commons licence, unless indicated otherwise in a credit line to the material. If material is not included in the article's Creative Commons licence and your intended use is not permitted by statutory regulation or exceeds the permitted use, you will need to obtain permission directly from the copyright holder. To view a copy of this licence, visit http://creativecommons.org/licenses/by/4.0/.

(C) The Author(s) 2021 